\title{
Perceived Vulnerability and Propensity to Adopt Best Management Practices for Huanglongbing Disease of Citrus in California
}

\author{
Sara Garcia-Figuera, ${ }^{1, \dagger}$ Holly Deniston-Sheets, ${ }^{2}$ Elizabeth Grafton-Cardwell, ${ }^{3}$ Bruce Babcock, ${ }^{4}$ \\ Mark Lubell, ${ }^{5}$ and Neil McRoberts ${ }^{1}$ \\ ${ }^{1}$ Department of Plant Pathology, University of California-Davis, Davis, CA 95616 \\ ${ }^{2}$ Data Analysis and Tactical Operations Center, Citrus Research Board, Visalia, CA 93291 \\ ${ }^{3}$ Department of Entomology, University of California-Riverside, Riverside, CA 92521 \\ ${ }^{4}$ School of Public Policy, University of California-Riverside, Riverside, CA 92507 \\ ${ }^{5}$ Department of Environmental Science and Policy, University of California-Davis, Davis, CA 95616 \\ Accepted for publication 16 February 2021.
}

\begin{abstract}
Huanglongbing (HLB) disease of citrus, which is associated with the bacterium 'Candidatus Liberibacter asiaticus', has been confined to residential properties in Southern California 8 years after it was first detected in the state. To prevent the spread of HLB to commercial citrus groves, growers have been asked to adopt a portfolio of voluntary best management practices. This study evaluates the citrus industry's propensity to adopt these practices using surveys and a novel multivariate ordinal regression model. We estimate the impact on adoption of perceived vulnerability to HLB, intentions to stay informed and communicate about the disease and various socio-economic factors, and reveal what practices are most likely to be jointly adopted as an integrated

groves. Most practices were perceived as complementary, particularly visual inspections and some combinations of preventive practices with tests and EDTs. Participants who felt more vulnerable to HLB had a higher propensity to adopt several practices, as did those who intended to stay informed and communicate with the coordinators of the HLB control program, although this effect was modulated by the perceived vulnerability to HLB. Communication with neighbors and the size of citrus operations also influenced practice adoption. Based on these results, we provide recommendations for outreach about HLB management in California and suggest future directions for research about the adoption of plant disease management practices.
\end{abstract} approach to HLB. Survey participants were in favor of scouting and surveying for HLB symptoms, but they were reluctant to test trees, use early detection technologies (EDTs), and install barriers around citrus
Keywords: Huanglongbing, biosecurity, adoption, best management practices, integrated pest management, risk perception
Since Huanglongbing (HLB) was first detected in the state of California in 2012 (Kumagai et al. 2013), the citrus industry has taken a proactive role in dealing with this devastating disease. In response to lobbying by and discussions with citrus industry leadership, the state legislature passed a bill in 2009 requiring the Secretary of Agriculture to establish the California Citrus Pest and Disease Prevention Committee (CPDPC). The CPDPC is composed of citrus industry representatives who make recommendations to the California Department of Food and Agriculture (CDFA), which then implements activities under its regulatory jurisdiction (De Leon 2009). Activities enforced by the CDFA, which include detection and removal of HLB-positive trees, are primarily funded by grower assessments of each carton of fruit harvested; however, because funds are limited, voluntary activities by commercial growers are also encouraged. A task force of grower representatives and researchers was appointed to collaboratively develop a Voluntary Grower Response Plan for Huanglongbing, which contains the best management practices recommended by the CPDPC to control the spread of HLB (CPDPP

${ }^{\dagger}$ Corresponding author: S. Garcia-Figuera; sgarciafiguera@ucdavis.edu

Funding: Support was provided by HLB MAC (AP17PPQS\&T00C058) and Citrus Research Board (5300-182 and 5300-192).

*The $\boldsymbol{e}$-Xtra logo stands for "electronic extra" and indicates that two supplementary figures, five supplementary tables, and supplementary materials are published online.

The authors declare no conflict of interest.

(c) (i) (-) $\ominus$ Copyright (C) 2021 The Author(s). This is an open access article distributed under the CC BY-NC-ND 4.0 International license.
2019). The voluntary plan was presented to the California citrus industry for the first time in 2019, at a series of industry seminars. We took the opportunity offered by those seminars to assess how likely it was that those practices would be adopted, evaluate what practices within the portfolio might be adopted together, understand what factors might influence adoption, and identify potential targets for outreach.

The adoption of best management practices by growers has been the subject of many studies and reviews (Liu et al. 2018; Prokopy et al. 2019). A common approach is to organize surveys, participatory workshops or interviews to assess the growers' willingness to adopt best management practices while gathering information about their personal and farm operation characteristics or other contextual factors that could help predict adoption (Prokopy et al. 2019; Puente et al. 2011). The adoption of agricultural practices in general has been found to be influenced by growers' attitudes toward the practices, financial motivations, problem awareness, information-seeking behavior, previous adoption of related practices, farm size, and income (Prokopy et al. 2019). For integrated pest management (IPM) in particular, early studies determined that IPM adoption by vegetable growers in the United States was influenced by farm size (Fernandez-Cornejo et al. 1994), whereas IPM adoption by coffee growers in Colombia was influenced by education and wealth (Chaves and Riley 2001). Over the years, other contextual factors have been found to impact IPM adoption, such as farm location and pest intensity (Kaine and Bewsell 2008), social networks and trusted sources of information (Hillis et al. 2016; Sherman and Gent 2014), and cost efficacy of the practices (Hillis et al. 2017).

Fewer studies have examined the socioeconomic and contextual factors that influence the adoption of management practices for invasive pests and diseases, which require quick decision-making to 
prevent spread but are associated with great uncertainty about risk and lack of previous experience (Simberloff et al. 2013). The two components of risk (likelihood of spread and establishment and potential negative impact) are commonly unknown at the time management decisions about invasive pests or diseases need to be made, which may lead to perceptions of risk to be subjectively constructed (McRoberts et al. 2011).

In the human disease literature, early behavioral models proposed that risk perception, comprising perceived vulnerability (how susceptible an individual felt to a communicated threat, related to likelihood) and perceived severity (how serious the individual believed the threat would be, related to impact), was a key factor in the decision to adopt self-protective behavior (Sheeran et al. 2017). One of the most widely accepted models, the protection motivation theory, proposed that the more vulnerable individuals perceived themselves to be to a threat, and the more serious they believed it to be, the more likely they would be motivated to protect themselves (Rogers 1975, 1985). Assuming that a similar cognitive process drove the intention to adopt protective behavior against plant and animal diseases, risk perception was also considered a key factor in predicting the adoption of management practices for these threats (Heong and Escalada 1999; Ritter et al. 2017).

However, the limited evidence available provides inconsistent support for a positive relationship between risk perception and adoption of management practices for invasive plant diseases. A Netherlands study showed that the adoption of management practices for several invasive diseases varied by crop, and that risk perception was negatively correlated with adoption (Breukers et al. 2012). The authors' interpretation was that growers who said they had experienced invasions and adopted management practices probably felt more protected, and thus perceived a lower risk of future invasions (Breukers et al. 2012). This negative feedback loop between protective behavior and risk perception had already been observed in studies of human diseases (Weinstein and Nicolich 1993). For example, people who received the Lyme disease vaccine showed a greater decline in their perceived risk of getting the disease than people who had not been vaccinated (Brewer et al. 2004).

As a result, three different hypotheses emerged in the human disease literature to describe the relationship between risk perception and self-protective behavior. The behavior motivation hypothesis, heir to the protection motivation theory, proposed that risk perception had a causal effect on the health behavior of individuals, so that a higher risk perception at one point in time would lead to increased health behavior in the future, as evidenced by a positive correlation between both factors in a longitudinal or experimental study (Brewer et al. 2004). The risk reappraisal hypothesis proposed that if an action were believed to reduce risk, then individuals who performed the action would subsequently lower their risk perception in the future, thus explaining the negative correlations found in the Netherlands study (Breukers et al. 2012) and the Lyme disease study (Brewer et al. 2004). Finally, the accuracy hypothesis proposed that individuals who engaged in risky behavior at a given point in time were at higher actual risk and would perceive a higher level of risk, as evidenced by a negative correlation between protective behavior and risk perception at that point in time (Brewer et al. 2004).

These three complementary hypotheses that emerged to explain positive or negative correlations between risk perception and protective behavior against human diseases highlight the importance of the time point when studies are conducted for interpreting results (Gaube et al. 2019); this has been rarely considered in the context of plant diseases. A study involving banana growers during the first few months after an outbreak of the invasive Panama tropical race 4 (TR4) disease in Australia showed that growers perceived a high level of risk, but it was not significantly correlated with proactive action against the disease (Mankad et al. 2019). The authors' interpretation was that fear of Panama TR4 was not the main motivation to engage in control, and other factors such as income dependency on bananas and perceived self-efficacy could be stronger predictors of the propensity to act. Considering the protection motivation theory and the adoption literature, these authors recommended that further studies should be performed to understand drivers of engagement in control against invasive plant diseases (Mankad et al. 2019).

This article uses HLB as a case study to examine the relationship between perceived vulnerability and grower adoption of management practices against invasive plant diseases at a unique point in time. HLB is an invasive bacterial disease that poses a major threat to citrus production worldwide (Wang 2019). Most commercial citrus cultivars are susceptible to HLB, and infected trees experience a rapid decline characterized by blotchy mottle symptoms on foliage, premature fruit drop and poor fruit quality, which lead to considerable economic losses before the eventual death of the tree (McCollum and Baldwin 2016). The most prevalent type of HLB is associated with the bacterium 'Candidatus Liberibacter asiaticus' (CLas), which is transmitted by grafting or by an insect vector, the Asian citrus psyllid (ACP), Diaphorina citri (Grafton-Cardwell et al. 2013). HLB has spread from Asia to the main citrus-producing regions in North America and South America, where it has had a devastating impact in Brazil (Bassanezi et al. 2020), Florida (Graham et al. 2020), Mexico (Robles González et al. 2018), and Texas (Sétamou et al. 2020).

HLB was first detected in California in 2012. Since then, $>2,000$ HLB-positive trees have been detected and removed from residential properties in Los Angeles, Orange, Riverside, and San Bernardino counties (CPDPP 2020b). Commercial citrus production is distributed between the Coastal and Southern counties, where the ACP is widespread, and the Central Valley, where there have been a few isolated ACP detections that have been quickly eradicated (Grafton-Cardwell 2020). Although HLB-positive trees have not yet been detected in any commercial citrus groves, a CLas-positive ACP was detected in a commercial grove in Riverside (CPDPP 2020a), and there is fear that positive tree detections will soon follow.

We contribute to the emerging interdisciplinary literature on the adoption of management practices for invasive plant diseases by assessing the California citrus industry's propensity to adopt a portfolio of voluntary management practices to prevent the spread of HLB. Through a survey distributed to 300 participants in three different grower meetings, we analyze adoption in a perennial cropping system after introduction of an invasive disease that cannot be eradicated, but before it has had an impact on commercial production. At this unique point in time, characterized by high risk and high uncertainty, we assess the citrus industry's perceived vulnerability to HLB, validate its accuracy based on geographical proximity to HLB detections, and show how it has changed over the course of the HLB epidemic in California, thus providing an update to a previous study (Milne et al. 2018). More importantly, we show how a multivariate ordinal regression model can be used to simultaneously evaluate the propensity to adopt a portfolio of management practices rated on an ordinal scale, assess the relationships among perceived vulnerability, information, communication, and propensity to adopt, and reveal which practices are more likely to be adopted together. Given the developing HLB situation in California, information to support strategic planning of the response is urgently needed. Based on the results of this study, we provide recommendations for outreach about HLB management in California and suggest future directions for research about the adoption of plant disease management practices more generally.

\section{MATERIALS AND METHODS}

Voluntary Grower Response Plan. The CPDPC appointed a task force of grower representatives and University of California (UC) researchers to assemble a set of voluntary best management practices that would be provided to the growers as a toolbox from which to choose practices to prevent the spread of HLB. Four hypothetical scenarios were defined by proximity to confirmed HLB detections to facilitate grower visualization of possible contexts for adoption. Specific protocols to implement the practices varied depending on the scenario. The Voluntary Grower Response Plan 
for Huanglongbing in California was officially published in May 2019 (CPDPP 2019); it was presented to the citrus community by the third author immediately before the survey that is the subject of this study.

The task force decided that early detection technologies (EDTs), which comprise any technology that can detect $C$ Las before the regulatory quantitative polymerase chain reaction (qPCR), should not be included in the portfolio of recommended practices because none of the EDTs was commercially available at the time when the plan was published. However, we decided to include EDTs in this study because at least one of them would be imminently available and evaluated (Gottwald et al. 2020), and at least that one was probably going to be considered by the citrus industry. For the same reason, we decided to also assess the propensity to use bactericides approved for CLas control, which have been tested against HLB and used in Florida (Al-Rimawi et al. 2019; Hu et al. 2018), even though they were not included in the Voluntary Grower Response Plan.

Theoretical framework. The propensity to adopt the recommended management practices for HLB in California was studied as a function of a set of predictor variables selected from the protection motivation theory, the technology adoption-diffusion literature, and similar studies of plant disease management.

The HLB management practices recommended by the Voluntary Grower Response Plan, with the addition of EDTs and bactericides, are the dependent variables in our regression model. To frame our analysis in the context of the IPM literature, eight selected practices were simplified and grouped into three categories: monitoring, prevention, and suppression. Monitoring and the proper identification of pests and diseases are considered the basis for IPM decisions (Farrar et al. 2016); this category includes scouting for ACP nymphs on flush, conducting visual surveys for HLB symptoms, voluntarily sending citrus leaves and ACP to be tested by an approved laboratory using a direct method of detection such as qPCR, and using EDTs. Prevention is defined as the practice of keeping a pest or disease from infesting a field or site (Farrar et al. 2016); this category includes adopting extra measures such as bags or repellents to protect new citrus plantings, using physical barriers such as mesh or windbreaks around the groves, and applying extra pesticides and repellents to the grove perimeters. Suppression is defined as the control of infestations or epidemics to prevent pest or disease levels from becoming economically damaging (Farrar et al. 2016); this category only includes the use of bactericides.

To align this study with the adoption literature, staying informed and communicating with the grower liaisons and communicating with neighbors, which are recommended by the Voluntary Grower Response Plan, were selected as explanatory factors related to actively seeking information and interacting with social networks, both of which have been found to be important determinants of the adoption of agricultural practices (Prokopy et al. 2019). The HLB control program in California has established a formal information network in which grower liaisons (individuals with local connections and experience as managers or advisors for the citrus industry) were hired as coordinators and knowledge brokers between the statewide program and citrus growers at the county or regional level. Therefore, we specifically chose to identify them as the main source of information about HLB. At the same time, informal networks have been repeatedly identified as relevant sources of information about agricultural practices (Hoffman et al. 2015); therefore, we included a question about communication between neighbors to test if informal information networks could be a relevant factor in the adoption of HLB management practices in California, as has been the case for other plant diseases (Maclean et al. 2019; Sherman et al. 2019).

A core hypothesis and four complementary hypotheses shaped the design of this study. According to the protection motivation theory, we expected the perceived vulnerability to HLB to have a positive impact on the propensity to adopt the recommended practices (H1). We chose to focus on the likelihood component of risk (i.e., perceived vulnerability) because we assumed that the citrus industry in California would be familiar with the high impact associated with HLB epidemics based on the widespread knowledge of the devastating consequences of HLB in Florida (Kuchment 2013). Compared with previous studies that measured the impact of risk perception on invasive plant disease management (Breukers et al. 2012; Mankad et al. 2019), this study was conducted at a time when participants already knew about the potential impact of an HLB epidemic in California. However, they did not have any experience implementing the recommended practices in commercial groves; therefore, we did not expect the accuracy hypothesis and the risk reappraisal hypothesis to be relevant to this case (Gaube et al. 2019). Therefore, we did not expect a negative relationship between perceived vulnerability and practice adoption.

We first aimed to evaluate whether the perceived vulnerability to HLB was accurate, and we compared it with the results of a previous survey conducted in 2015 (Milne et al. 2018). Then, we expected the participants' perceived vulnerability to HLB to have a positive regression coefficient for the eight practices considered in the multivariate ordinal regression model because they would all improve the level of protection against HLB. In particular, we expected perceived vulnerability to have a positive impact on the adoption of monitoring practices because people who feel more vulnerable to HLB might have a greater need to know the status of the disease in their fields.

In line with previous adoption studies, we expected the propensity to stay informed and communicate with grower liaisons to have a positive impact on the propensity to adopt the recommended practices $(\mathrm{H} 2)$. Again, a positive relationship could be expected for all the practices considered; however, we expected it to be particularly noticeable for some of the monitoring practices because the HLB control program and the grower liaisons have been promoting these practices since the beginning of the HLB epidemic in California. In fact, this hypothesis allowed us to examine the level of acceptance and potential effectiveness of the grower liaisons as sources of information and promoters of the HLB control program.

Because HLB is an invasive disease that can rapidly spread across a landscape and requires coordination beyond property boundaries for effective control (Bassanezi et al. 2013; Graham et al. 2020), we expected communication with neighbors to have an impact on the propensity to adopt some of the recommended practices for HLB (H3), and we were interested in determining the sign of the coefficient for this impact for different practices. Communication between neighbors might facilitate sharing positive experiences and ultimately foster the adoption of beneficial practices (Sherman et al. 2019); however, at the same time, lack of intention to communicate with neighbors might indicate distrust and motivate the adoption of practices to provide protection against inoculum coming from neighbors (Maclean et al. 2019). We were also interested in identifying what practices were positively impacted by communication with neighbors because they might be more likely to be adopted in a coordinated manner. Previous studies have shown that face-to-face communication is essential to develop trust and reciprocity to coordinate efforts in plant disease management (Sherman et al. 2019). Growers who were active participants in their community were more willing to cooperate to control pests than those who were not active members (Stallman and James 2015).

Individual socioeconomic factors were expected to modulate the propensity to adopt some of the recommended practices (H4). Land tenure has been identified as a determinant of the adoption of many agricultural practices (Prokopy et al. 2019); therefore, we expected grove owners to have a different propensity than other citrus stakeholders to adopt some practices. In particular, grove owners might be less willing to invest in adopting practices that are more expensive, such as installing barriers along the grove perimeter, which would require the removal of productive trees to make space for the barriers. Also, if voluntary tests lead to the identification of an HLB-positive tree that would trigger a quarantine, then it might have significant economic consequences for the owner; therefore, we hypothesized that grove owners might be less willing to test. Farm size has been 
consistently associated with increasing levels of adoption for many agricultural practices because larger farms have more financial capital and may have lower adoption thresholds in relation to cost and time to a return on their investment (Prokopy et al. 2019). Therefore, we expected farm size to have a significant and positive impact on the propensity to adopt the recommended practices for HLB. In line with previous studies (Prokopy et al. 2019), we expected that age would have a negative impact on adoption because older growers might consider shorter time horizons and be less willing to make investments to protect themselves against HLB. The general feeling among the citrus industry in California is that conventional and organic growers differ in their approach to control citrus pests and diseases; therefore, we were interested in testing whether this factor had a significant impact on the adoption of HLB management practices. Finally, we expected that participants who obtained a higher percentage of their income from citrus would have a higher propensity to adopt practices to manage HLB, as noted by previous studies (Mankad et al. 2019; Stallman and James 2015).

Because the Voluntary Grower Response Plan was conceived as a toolkit for HLB management, we expected the adoption of HLB management practices to be interdependent (H5), which would be indicated by significant correlations between the adoption equations for different practices in a multivariate ordinal logistic regression model. Our expectation was that some of the practices belonging to the same IPM category would have a higher propensity to be adopted together, which would be indicated by significant positive correlations for the equations within each group. For example, within the category of monitoring practices, we expected people who were likely to scout for ACP nymphs on flush to also be likely to conduct visual surveys for HLB symptoms because both practices could be implemented simultaneously and they provide complementary information about the vector and the disease. Because EDTs are a new technology for citrus growers, we were interested in determining if they were being perceived as complementary to other monitoring practices such as surveying for symptoms or testing. For preventive practices, it was unclear a priori if installing physical barriers along the grove perimeter would be perceived as complementary or a substitute for applying pesticides and repellents to the perimeter or taking extra measures to protect new plantings.

Survey design. The survey to assess the citrus stakeholders' propensity to adopt HLB management practices was designed by the authors and consisted of 20 questions (Supplementary text S1). The first six questions referred to the participants' social and economic background and were based on available data (USDA-NASS 2018) or previous similar studies (Mankad et al. 2019; Milne et al. 2018; Singerman et al. 2017; Stallman and James 2017). For these questions, participants were asked to select from a list the categorical responses that most closely represented their situation. First, they were asked to indicate their role in citrus production, choosing among grove owner, ranch manager, pest control adviser (PCA; who is a professional consultant licensed by the State of California to provide pest management recommendations), pest control operator ( $\mathrm{PCO}$; who is a person or company licensed to apply agricultural pesticides to crops), and other. Second, participants were asked to indicate how many acres of citrus they grew or managed (farm size), choosing among $<5,5$ to 25,26 to 100,101 to 500 , and $>500$ acres. Third, they were asked about their age group (younger than 35,35 to 50,51 to 65 , and older than 65 years). Fourth, they were asked to indicate any California counties in which they had managed or currently managed groves, choosing between Fresno, Imperial, Kern, Madera, Riverside, San Bernardino, San Diego, Santa Barbara, Tulare, and Ventura. Fifth, they were asked to indicate whether they grew citrus conventionally, organically, or both (management system). Finally, they were asked to indicate what percentage of their income came from citrus ( 0 to 25,26 to 50,51 to 75 , and 76 to $100 \%$ ).

To assess their perceived vulnerability to HLB, participants were asked, "How likely do you think it is that an HLB-positive tree will be detected in your grove in the next year (July 2019 to June 2020)?" This question was in line with those asked in human disease studies (Brewer et al. 2004), and it was based on a similar question asked in 2015 (Milne et al. 2018) to provide an update to the citrus stakeholders' perceived vulnerability to HLB 4 years into the epidemic. The rest of the questions assessed the participants' propensity to adopt the best management practices recommended by the CPDPC. The wording of the practices was simplified for the survey, as indicated in the previous section, and the propensity to adopt was assessed as "How likely is it that you will ... ?". Ordinal responses were provided using a 5-point scale of very unlikely, unlikely, maybe, likely, and very likely. For two of the questions ( 8 and 17), a sixth option (do not know who the liaison is and do not have enough information, respectively) was added to identify participants who thought they lacked enough information to make a choice.

The research protocol was submitted to the Institutional Review Board (IRB) at University of California Davis, and it was granted exempt status because it entailed low risk for the participants.

Survey distribution. The survey was distributed at three grower meetings that were part of the Citrus Growers Educational Seminar Series organized by the Citrus Research Board (CRB) in conjunction with the University of California Cooperative Extension (UCCE) in June 2019 in Palm Desert (southeast California), Santa Paula (coastal California), and Exeter (Central Valley). These are annual seminars organized by the CRB/UCCE that provide attendees with continuing education units and certified crop adviser hours. The availability of these credits tends to result in a larger than usual attendance for grower workshops, thereby reducing selection bias toward only those with a particular interest in a given topic. Selection bias was further limited by the fact that the annual election of citrus industry representatives for the $\mathrm{CRB}$ was scheduled on the day of the seminars in Palm Desert and Exeter. The three meetings had the same format. The survey was distributed directly after a presentation of the Voluntary Grower Response Plan for Huanglongbing. At the time when the meetings were held during a single week in June 2019, 1,484 trees had been confirmed to be infected with HLB in California since the first detection in 2012; all of them were on residential properties (7 in Riverside County, 387 in Los Angeles County, and 1,090 in Orange County) (CPDPP 2020b).

The survey was introduced to the participants as voluntary and anonymous, in compliance with IRB regulations. It was presented using the TurningPoint add-in for Microsoft PowerPoint (Microsoft, Redmond, WA, U.S.A.), and the responses were collected using clicker handsets from TurningPoint (Turning Technologies, Youngstown, OH, U.S.A.) that had been given to each participant before the seminar started. Participants were given approximately $1 \mathrm{~min}$ to answer each question. When the polling time was closed for each question, a summary of the responses (percentage of participants who had chosen each response) was shown to the audience and briefly discussed before moving to the next question.

In total, we collected responses from 300 participants. The average number of responses for any question of the survey was 225 (an average response rate of $75 \%$ per question). In Palm Desert, there were 95 registered attendees of the meeting, and responses were collected from 59 participants. In Santa Paula, there were 131 registered attendees, and responses were collected from 91 participants. In Exeter, there were 219 registered attendees, and responses were collected from 150 participants. Across the three meeting locations, 160 people answered a sufficient number of questions (perceived vulnerability, communication, relevant socioeconomic factors, and at least one practice) to be considered for statistical analysis.

Descriptive statistics of the survey respondents. The respondent sample provided reasonable coverage of the citrus industry in California (Table 1). Among the 160 people who answered a sufficient number of questions in the survey to be considered for analysis, $44 \%$ were grove owners, $18 \%$ were ranch managers, $16 \%$ were PCAs, and 2\% were PCOs. The rest (20\%) self-identified as other, 
which could include packers, haulers, regulators, or university employees. Compared with the size distribution of orchards in the counties represented in the survey, small operations ( $<5$ acres) were underrepresented, comprising $15 \%$ of the sample compared with $34 \%$ of orchards in those counties, and big operations ( $>500$ acres) were overrepresented, comprising $38 \%$ of the sample compared with $18 \%$ of orchards in those counties (USDA-NASS 2019). Most participants (54\%) were between 35 and 65 years of age, which is the most common $(56 \%)$ age range for growers in California (USDA-NASS 2019). Participants younger than 35 were overrepresented in the survey (17 versus 6\%), and participants older than 65 were slightly underrepresented (29 versus $38 \%$ ) (USDA-NASS 2019). The majority of participants (71\%) grew citrus conventionally, a few (4\%) grew citrus organically, and some (25\%) grew citrus under both management systems. This is representative of citrus production in California because it is estimated that approximately $8 \%$ of citrus operations and $3 \%$ of acreage in the state are certified organic (USDA-NASS 2017, 2019).

Approximately one-third $(38 \%)$ of participants indicated that $<25 \%$ of their income came from citrus, whereas another approximately one-third (35\%) indicated that $>75 \%$ of their income came from citrus. Participants had groves in the top 10 citrus-producing counties in California (from higher to lower acreage): Tulare (130,341 acres); Kern (66,720 acres); Fresno (56,326 acres); Ventura (18,447 acres); Riverside (17,333 acres); San Diego (11,701 acres); Imperial (10,328 acres); Madera (2,800 acres); San Bernardino (2,435 acres); and Santa Barbara (1,291 acres) (Fresno CAC 2019; Imperial CAC 2019; Kern CAC 2019; Madera CAC 2019; Riverside CAC 2019; San Bernardino CAC 2019; San Diego CAC 2019; Santa Barbara CAC 2019; Tulare CAC 2019; Ventura CAC 2019). Because participants were asked to indicate any counties in which they had groves (multiple response option), counties were grouped in three regions to simplify some of the analyses: Coast (38\%), which

TABLE 1 . Socioeconomic characteristics of the survey respondents $(n=160)^{\mathrm{a}}$

\begin{tabular}{|c|c|c|}
\hline Survey item & Responses & $\begin{array}{c}\text { Percentage } \\
\text { of total }\end{array}$ \\
\hline \multicolumn{3}{|l|}{ Role in citrus production } \\
\hline Grove owner & 68 & 43 \\
\hline Ranch manager & 27 & 17 \\
\hline Pest control adviser & 24 & 15 \\
\hline Pest control operator & 3 & 2 \\
\hline Other & 31 & 19 \\
\hline \multicolumn{3}{|l|}{ Farm size, acres } \\
\hline$<5$ & 24 & 15 \\
\hline $5-25$ & 30 & 19 \\
\hline $26-100$ & 21 & 13 \\
\hline $101-500$ & 24 & 15 \\
\hline$>500$ & 61 & 38 \\
\hline \multicolumn{3}{|l|}{ Age, years } \\
\hline$<35$ & 27 & 17 \\
\hline $35-50$ & 29 & 18 \\
\hline $51-65$ & 57 & 36 \\
\hline$>65$ & 47 & 29 \\
\hline \multicolumn{3}{|l|}{ Region } \\
\hline Coast & 61 & 38 \\
\hline SoCal & 35 & 22 \\
\hline Valley & 64 & 40 \\
\hline \multicolumn{3}{|l|}{ Management system } \\
\hline Conventional & 113 & 71 \\
\hline Organic & 7 & 4 \\
\hline Both & 39 & 24 \\
\hline \multicolumn{3}{|l|}{ Income from citrus, $\%$} \\
\hline$<25$ & 58 & 38 \\
\hline $26-50$ & 20 & 13 \\
\hline $51-75$ & 21 & 13 \\
\hline $76-100$ & 54 & 34 \\
\hline
\end{tabular}

${ }^{\text {a }}$ Although the dataset that was used for the analyses included the responses from 160 participants, not all of them answered every socioeconomic question. included Ventura, Santa Barbara, combinations of Ventura and Santa Barbara, and Ventura and Tulare; Southern California or SoCal (22\%), which included Imperial, Imperial and Riverside, Imperial and San Diego, Riverside, Riverside and Kern, Riverside and San Diego, Riverside and Ventura, San Bernardino, San Bernardino and Fresno, San Bernardino and San Diego, San Bernardino and Ventura, and San Diego and Santa Barbara; and the Central Valley or Valley (40\%), which included Fresno, Fresno and Kern, Fresno and Madera, Fresno and Tulare, Kern, Kern and Tulare, Madera, Madera and Tulare, and Tulare.

Statistical analysis. All statistical analyses were performed using the $\mathrm{R}$ programming environment version 3.5.3 (R Foundation for Statistical Computing 2019) with a Windows 10 Pro version 1909, 64-bit operating system (Microsoft, Redmond, WA, U.S.A.). Differences in the distribution of responses to a question based on the groups defined by responses to another question were tested using the Kruskal-Wallis test. Pairwise comparisons of the distribution of responses between two groups were tested using the nonparametric Wilcoxon-Mann-Whitney test. Plots were created using the R package "ggplot2" (Wickham 2016) with the complementary packages "likert" (Bryer and Speerschneider 2016), "lemon" (McKinnon Edwards et al. 2020), and "ggraph" (Pedersen 2020).

Grove owners, ranch managers, PCAs, PCOs, and other participants did not have significantly different distributions of responses to most questions; therefore, all categories were considered for analysis and may be referred to as "participants," "respondents," or "growers." In terms of correlations among socioeconomic factors, farm size was positively correlated with the percentage of income from citrus $\left(\rho=0.56 ; P=2.84 \times 10^{-14}\right)$, and older participants tended to manage smaller groves $\left(\rho=-0.27 ; P=7.04 \times 10^{-4}\right)$. However, these two factors were not included at the same time in the selected model; therefore, these correlations did not interfere with the interpretation of our results.

Relating perceived vulnerability to HLB with an objective assessment of the likelihood of HLB detection. To assess whether the participants' perceived vulnerability to HLB (i.e., likelihood of HLB detection in their grove in the next year) was accurate, we compared it with an objective measure of the likelihood of HLB detection based on their geographical location. The location of the citrus groves in each county was taken from the commercial GIS citrus layer developed by the CRB (R. Dunn, personal communication). In the absence of individual-level coordinates for each participant's groves, the centroid of the citrus production area in the county where participants said they had groves was used as the point of origin, and we calculated the linear distance from each centroid to the closest confirmed HLBpositive tree anywhere in Southern California. For participants who indicated that they had groves in more than one county, we used the average distance from the centroid of the citrus production areas in the two counties indicated by the participant to the closest HLB detection. In addition, we calculated the average, minimum, and maximum distance from any grove registered in the CRB citrus layer in any of the counties indicated by the participants to the closest HLB-positive tree. Centroids and distances were calculated using ArcGIS Pro (Esri, Redlands, CA, U.S.A.). Then, distances were correlated with the perceived vulnerability indicated by the participants, on a numerical scale, using Spearman's rank correlation test. The coordinates of the HLB-positive trees were obtained from the database maintained by CDFA under terms of a data confidentiality memorandum of understanding among the CDFA, the UC, and CRB. Location-specific data for HLB-positive trees in California are confidential and cannot be shared in public documents.

Evaluating the impact of perceived vulnerability, information, communication, and socioeconomic factors on the propensity to adopt, and the interdependence between practices. To take a first look at relationships between pairs of practices and between practices and explanatory factors, we calculated Spearman's rank correlation coefficients $(\rho)$ and their associated $P$ 
values using the R package "Hmisc" (Harrell and Dupont 2020). To perform these analyses, responses to questions that were expressed using an ordinal scale (i.e., questions 2 to 4,6 to 11 , and 13 to 20) were transformed to numeric (very unlikely $=1$, unlikely $=2$, maybe $=3$, likely $=4$, and very likely $=5$ ).

Because some of the recommended practices may be interdependent, either as complements or as substitutes, using univariate ordinal regression models to predict the propensity to adopt each practice separately according to the selected explanatory factors may lead to inaccurate conclusions, since they ignore potential interdependencies between practices that are the basis of an IPM approach. To address this limitation, we investigated the use of a multivariate ordinal regression model (Hirk et al. 2019). To our knowledge, this is the first time that this type of model has been used in the context of practice adoption in plant disease management. The model is based on the idea that there is a latent variable that captures the utility of adopting practices (against HLB in this case), which was assessed through ordinal ratings. This latent variable is assumed to be a linear combination of observed explanatory factors and unobserved factors captured by a stochastic error term (Greene and Hensher 2010). Model parameters are estimated through composite likelihood methods. By using a cumulative logit link model, regression coefficients can be interpreted in terms of log odds ratios, and the error terms are assumed to jointly follow a multivariate logistic distribution (Hirk et al. 2019). By simultaneously considering the influence of explanatory factors on each of the different practices, while allowing the unobserved or unmeasured factors to be freely correlated, the model estimates a correlation matrix between practices whereby the coefficients indicate the polychoric correlations between the latent utilities of each pair of practices. Polychoric correlations are defined as the correlations between each pair of latent continuous variables that have been assessed through discrete ordinal ratings (Greene and Hensher 2010). If any correlation coefficient $\rho_{i j}$ is significantly positive, it will indicate a complementary relationship between practices $i$ and $j$. Conversely, if $\rho_{i j}$ is significantly negative, it will indicate a substitute relationship between practices $i$ and $j$ (Cai et al. 2019; Hirk et al. 2019). Therefore, the model can estimate which practices within the recommended portfolio are likely to be adopted together once explanatory factors have been considered.

The multivariate ordinal regression model was fitted using the $\mathrm{R}$ package "mvord" (Hirk et al. 2020) to the eight practices recommended by the CPDPC, for which propensity to adopt was evaluated using a 5-point ordinal scale from very unlikely to very likely. Perceived vulnerability was included in the model as a numeric explanatory factor, the propensity to stay informed and communicate with the grower liaison or to communicate with neighbors were included as numeric explanatory factors, and socioeconomic factors were included as categorical or numeric explanatory factors. Categorical socioeconomic factors (role and management system) were transformed to binary so that being a grove owner would correspond to 1 and the rest of the options would correspond to 0. Similarly, growing citrus conventionally would correspond to 1 and growing citrus organically, or both conventionally and organically, would correspond to 0 . Ordered socioeconomic factors (acreage, age, and income) were initially included as ordered factors to test their linear effect on adoption using orthogonal polynomial coding. Once the linear effect was verified, they were transformed to numeric so that the first response category would correspond to 1 , the second would correspond to 2, and so on. Multicollinearity between explanatory factors was first examined through Spearman rank correlations and then checked through variance inflation factors (VIF) and condition indexes $(\mathrm{CI})$, assuming that the ordinal ratings were numeric values (Daxini et al. 2018). VIFs and CIs did not indicate that there were severe multicollinearity problems in the dataset; therefore, all factors were considered for the regression analyses. To choose the most parsimonious model, models with different explanatory factors, thresholds, regression coefficients, and error structure specifications were compared using McFadden's pseudo $R^{2}$ (McFadden 1974), a
Composite Likelihood Bayesian Information Criterion (CLBIC) (Hirk et al. 2019), and likelihood ratio tests (Greene and Hensher 2010), calculated with the R package "Imtest" (Zeileis and Hothorn 2002).

The probability of being likely or very likely to adopt each practice according to each explanatory factor was calculated using the formula of the selected multivariate ordinal regression model with the threshold parameter corresponding to the change between the categories maybe and likely and the estimated regression coefficients of the explanatory factors for each practice, fixing each factor except the one being evaluated at their mean value. With this formula, we calculated the log odds of answering maybe or less for each practice, which were transformed to an odds value, and then to a probability value corresponding to $P(Y \leq$ maybe $)$. The probability of answering likely or very likely was calculated as the complement of that value, so $P(Y>$ maybe $)=1-P(Y \leq$ maybe $)($ Greene and Hensher 2010).

\section{RESULTS}

The perceived vulnerability to HLB has declined over the course of the epidemic, but it is correlated with an objective assessment of the likelihood of HLB detection. The first goal of this study was to assess the California citrus industry's perceived vulnerability to HLB (i.e., likelihood of HLB detection in their grove in the coming year) to determine if it was related to their self-reported propensity to adopt the best management practices recommended by the CPDPC. We also wanted to test if the perceived vulnerability to HLB was accurate and to compare the answers to this question with a similar survey that was conducted in 2015 (Milne et al. 2018) to determine if there had been any changes in perceived vulnerability after 4 years of HLB spread in California.

Across the three main citrus-growing regions in California, the majority $(71 \%)$ of respondents thought that it was unlikely or very unlikely that an HLB-positive tree would be detected in their grove in the next year (from July 2019 to June 2020). Only 7.5\% thought that an HLB detection was likely or very likely. The likelihood of HLB detection varied with the region of origin $\left(P=3.54 \times 10^{-7}\right.$ for the Kruskal-Wallis test), and pairwise comparisons among regions showed that there was a significant difference between the Valley and the Coast $\left(P=2.74 \times 10^{-7}\right.$ for the Wilcoxon-Mann-Whitney test $)$ and between the Valley and SoCal $\left(P=4.71 \times 10^{-5}\right)$. In the Valley, most participants $(91 \%)$ believed that it was unlikely or very unlikely that there would be an HLB detection in their grove in the next year, whereas fewer people believed that in the Coast $(54 \%)$ or in SoCal (63\%), reflecting regional differences in perceived vulnerability.

To compare the respondents' perceived vulnerability to an objective assessment of the likelihood of detecting the disease, we calculated the distance from the centroid of the citrus production areas in the county that they indicated, or the average distance between the two counties indicated, to the closest HLB positive tree confirmed by CDFA (Fig. 1; Supplementary Table S1). Distances were then correlated with the likelihood of HLB detection indicated. As expected, the perception of the likelihood of an HLB detection in their grove in the coming year was negatively correlated with distance from an HLB-positive tree $(\rho=-0.32 ; P=0.019)$ Similar correlation coefficients were obtained when using the average distance $(\rho=-0.32$; $P=0.017)$ and maximum distance $(\rho=-0.30 ; P=0.024)$ from any grove in any of the counties indicated by the participants, but not when using the minimum distance $(\rho=-0.26 ; P=0.054$ ) (Supplementary Fig. S1). Therefore, in general, participants who were further away from confirmed cases of HLB thought that the probability of finding HLB in their grove was lower, and participants who were closer to HLB-positive trees thought that the probability was higher. This pattern of responses seems to reflect a rational relationship between perceived vulnerability and actual probability of infection.

Because HLB is an invasive disease that is spreading in California, the participants' perception of the likelihood of an HLB detection in 
their grove was expected to influence their propensity to adopt some of the practices recommended by the CPDPC. Indeed, the likelihood of detecting HLB was positively correlated with scouting for ACP on flush $(\rho=0.29 ; P=0.0002)$, surveying for HLB symptoms $(\rho=0.16$; $P=0.04)$, and voluntarily testing trees and $\operatorname{ACP}(\rho=0.26 ; P=0.001)$. Therefore, participants who perceived a higher likelihood of detecting HLB seemed to be more willing to scout, survey, and test, which are three monitoring practices directly aimed at detecting HLB. Remarkably, the perceived likelihood of HLB detection was not correlated with the propensity to adopt any of the other practices.

In addition, we calculated the correlation between distance to confirmed HLB-positive trees and propensity to adopt the practices recommended by the CPDPC (Table 2). All correlation coefficients were negative, indicating that participants who were further away from HLB-positive trees were less likely, in general, to adopt any of the practices, and those who were closer were more likely to consider them. Distance from HLB was negatively and significantly correlated
TABLE 2. Spearman rank correlations between the propensity to adopt the recommended practices and the average distance from the centroid of the citrus acreage in each county or counties to the closest tree confirmed to be Huanglongbing (HLB)-positive by the California Department of Food and Agriculture (Fig. 1)

\begin{tabular}{lcc}
\hline Question & $\begin{array}{c}\text { Correlation } \\
\text { coefficient }\end{array}$ & $P$ \\
\hline Perceived vulnerability & -0.40 & $1.12 \mathrm{E}-07$ \\
Stay informed and communicate with liaison & -0.22 & 0.005 \\
Communicate with neighbors & -0.18 & 0.022 \\
Protect new plantings & -0.09 & 0.286 \\
Barriers & -0.19 & 0.018 \\
Repellents applied to perimeter & -0.05 & 0.559 \\
Scout for Asian citrus psyllid on flush & -0.39 & $4.40 \mathrm{E}-07$ \\
Survey for HLB symptoms & -0.28 & $3.04 \mathrm{E}-04$ \\
Test (quantitative polymerase chain reaction) & -0.16 & 0.044 \\
Early detection technologies & -0.17 & 0.038 \\
Bactericides & -0.10 & 0.215 \\
\hline
\end{tabular}



Fig. 1. Distance from the centroid of the citrus acreage in each county to the closest Huanglongbing (HLB)-positive tree detected by the California Department of Food and Agriculture (CDFA). The areas shaded in black represent the citrus production areas according to the Citrus Research Board (CRB) database (R. Dunn, personal communication). The black dots represent the coordinates of the centroid of those citrus production areas in each county. The blue dashed lines represent the distance from the centroids to the closest HLB-positive tree (actual distances are shown in Supplementary Table S1). The coordinates of the HLB-positive trees were obtained from the Citrus Pest and Disease Prevention Program (CPDPP) database maintained by the CDFA under terms of a data confidentiality memorandum of understanding between CDFA, the University of California, and CRB. The perimeter of the HLB quarantine zone at the time of the survey is shown in blue (R. Johnson, personal communication). The counties where survey participants had citrus groves have been labeled and colored in shades of orange according to the total citrus acreage harvested in each county during 2018 (Fresno CAC 2019; Imperial CAC 2019; Kern CAC 2019; Madera CAC 2019; Riverside CAC 2019; San Bernardino CAC 2019; San Diego CAC 2019; Santa Barbara CAC 2019; Tulare CAC 2019; Ventura CAC 2019). 
with staying informed and communicating with the grower liaison, communicating with neighbors, protecting new plantings, applying repellents to the perimeter, surveying for HLB symptoms, and considering the use of EDTs. However, the propensity to install barriers, scout for ACP on flush, voluntarily test, or consider the use of bactericides did not significantly increase as participants got closer to HLBpositive trees.

Finally, we compared the answers obtained in 2019 with those of a similar survey that was distributed during analogous meetings in 2015 (Milne et al. 2018). At that time, participants were asked how likely they thought it was that their groves would be infected with HLB within 5 years, which corresponded to the year 2020. The respondent sample was similar between both surveys in terms of farm size, county of origin, and management system; therefore, we believe that differences in the perceived likelihood of HLB detection between the surveys might indicate changes in perception among citrus stakeholders in California. However, we note that both surveys consisted of a nonrandom sample of citrus stakeholders, and there may have been selection bias toward people who were engaged in HLB and ACP management.

In 2015, the perceived likelihood of HLB detection by 2020 was significantly associated with the location of groves. Participants with groves in San Bernardino, Riverside, San Diego, and Imperial counties (SoCal) thought they would almost certainly be infected by 2020 ; participants from the Coast thought it was possible or likely; and participants from the Central Valley thought it was unlikely or possible (Milne et al. 2018). Four years later, we noticed a shift toward thinking that HLB detection is unlikely or very unlikely. While in the 2015 survey, $26 \%$ of respondents statewide thought that it was unlikely or very unlikely that an HLB-positive tree would be detected in their grove by 2020 (Milne et al. 2018), in the 2019 survey, 71\% of participants thought that an HLB detection in their grove was unlikely or very unlikely in the coming year (from July 2019 to June 2020). Therefore, our results appear to show that the majority of the citrus industry believes that the epidemic is not progressing as fast as they thought it would 4 years ago.

Propensity to adopt the best management practices for HLB. The second goal of the survey was to assess the propensity to adopt the best management practices recommended by the CPDPC as they were introduced to the California citrus industry for the first time. Because these practices were envisioned as a toolkit, the ultimate intention was not only to assess the participants' propensity to adopt these practices individually, but also to determine which practices were likely to be adopted together (H5), and assess the impact that perceived vulnerability $(\mathrm{H} 1)$, propensity to stay informed and communicate (H2, H3), as well as individual socioeconomic factors (H4) might have on adoption. To achieve this, we first examined the responses through rank tests and correlation analyses; and then used a multivariate ordinal regression model to evaluate the propensity to adopt the eight recommended practices simultaneously.

At first glance, it was clear that not all of the practices had equal probability of being adopted (Fig. 2). Overall, the majority of participants were likely or very likely to survey for HLB symptoms (74\%) and scout for ACP on flush (68\%), but they were unlikely or very unlikely to install physical barriers along grove perimeters (71\%), to voluntarily test trees and ACP (53\%), and to use EDTs (54\%). Remarkably, most participants said that they were likely or very likely to stay actively informed about HLB and communicate with their grower liaison $(79 \%)$ and to communicate with neighbors $(65 \%)$, suggesting engagement with both formal and informal information networks.

As mentioned, the eight practices were classified into three IPM categories: monitoring, prevention and suppression. Practices related to visual monitoring had a higher propensity to be adopted than preventive, suppressive, and more complex monitoring practices. Because an integrated approach to HLB would involve combinations of all these practices, we sought to investigate how they were being perceived in relation to the rest of the toolkit and what factors could impact adoption in subsequent analyses.
Determinants of the propensity to adopt best management practices for HLB. To test the impact that perceived vulnerability, disposition to stay informed and communicate with the grower liaisons, disposition to communicate with neighbors, and socioeconomic circumstances could have on the adoption of HLB management practices, these variables were included as explanatory factors in a multivariate ordinal logistic regression model. Among several model specifications, the most parsimonious one used a logit link function and assumed that the threshold parameters between propensity-toadopt categories were the same for all practices and participants, that regression coefficients were specific to each practice, and that there was a general correlation structure between the error terms (Hirk et al. 2019). The participants' perceived vulnerability to HLB, their propensity to stay informed and communicate with the grower liaison, their propensity to communicate with neighbors, and farm size were included as numeric explanatory factors. We also included an interaction term between perceived vulnerability and propensity to stay informed and communicate to determine if providing information to growers fostered adoption under different vulnerability scenarios. Because differences in perceived vulnerability were associated with the region of origin, and because there was a strong correlation between perceived vulnerability and distance from HLB-positive trees, we decided to discard region and distance from HLB as explanatory factors and chose to focus on perceived vulnerability. The other explanatory factors were also discarded during model selection because they did not significantly improve model fit according to likelihood ratio tests (Supplementary Table S2). The most parsimonious model had a CLBIC of 26,506 and a McFadden's adjusted pseudo $R^{2}$ of $0.0291(\mathrm{df}=583.8)$. All the explanatory factors had a significant impact on at least one practice. This model did not have significantly lower fit than the model with all explanatory factors, and it significantly improved fit compared with models with fewer explanatory factors $(P=0.0032)$ and the model with no predictors $\left(P<2.2 \times 10^{-16}\right)$, which had a CLBIC of 26,817 and an adjusted pseudo $R^{2}$ of $-0.085(\mathrm{df}=81.73)$.

In the most parsimonious model, there was a significant effect of perceived vulnerability, disposition to stay informed and communicate with both liaisons and neighbors, and farm size on one or more practices. There was also a significant interaction between perceived vulnerability and propensity to stay informed and communicate with the liaison (Fig. 3; Supplementary Table S3).

As hypothesized, the estimated likelihood of HLB detection in a citrus grove in the coming year (perceived vulnerability) had a positive impact on the participants' propensity to adopt most of the HLB management practices (H1). This indicates that participants who felt more vulnerable to HLB were more likely to protect their citrus groves, which is in line with the protection motivation theory. The exception was the use of EDTs, for which there was no apparent relationship with perceived vulnerability. The coefficients were positive and significant with $90 \%$ confidence for scouting for ACP, protecting replants, treating grove perimeters, and using bactericides (Fig. 3). Therefore, for a one unit increase in perceived vulnerability, the odds that someone would be more likely to protect new citrus plantings were $4.7[\exp (1.55)]$ times higher, 3.8 higher for scouting for ACP on flush, 2.7 times higher for treating the grove perimeter and 2.8 times higher for using bactericides. Interestingly, people who felt more vulnerable to HLB did not have significantly higher odds of testing their trees or surveying for HLB symptoms, suggesting that they were not willing to put more effort into detecting the disease.

As expected, the intention to stay informed and communicate with the grower liaison had a positive impact on the propensity to adopt all of the practices, and it was significant in most cases (H2). Participants who were more likely to seek information and be engaged with the regional coordinators of the HLB control program had significantly higher odds of adopting monitoring practices such as scouting for ACP and surveying for HLB symptoms, preventive practices such as protecting new plantings, installing barriers around citrus groves, 
and applying pesticides or repellents to the perimeter, as well as using bactericides. This confirms that the formal network that was created by the CPDPC might be effective for promoting the adoption of most practices. However, more engagement with the control program did not lead to a significantly higher odds of testing or using EDTs, indicating that alternative strategies might be required to foster the adoption of these two tools.

Moreover, we detected a significant interaction between the participants' intention to stay informed and communicate with the grower liaison and their perceived vulnerability to HLB on the adoption of two practices. This indicates that the benefits of promoting HLB management through the CPDPC outreach network might depend on how vulnerable citrus growers feel to HLB and, therefore, on the stage of the HLB epidemic. Positive regression coefficients of the interaction term would indicate a synergistic effect in which higher vulnerability and more information and communication act together to encourage further adoption than any of the two explanatory factors alone, whereas negative coefficients would indicate that the two factors may act against each other. Neither of the two positive interaction effects were significant, but two of the six negative ones were. This suggests that the odds of protecting replants or applying pesticides and repellents to the perimeter might only increase with information and interaction with the grower liaisons under low perceived vulnerability to HLB, and the trend may change under higher vulnerability scenarios.

The propensity to adopt some HLB management practices was also impacted by the intention to communicate with neighbors $(\mathrm{H} 3)$, but the sign of this impact varied for each practice. For most practices it was positive, meaning that participants who were more likely to communicate with neighbors had higher odds of adoption, but it was only significant for two practices. A one-unit increase in the intention to communicate with neighbors led to 1.6-times and 1.33times higher odds of surveying for HLB symptoms and using EDTs, respectively, indicating that informal networks might be a pathway to promote the adoption of these tools.

In terms of the impact that the participants' socioeconomic circumstances could have on their propensity to adopt HLB management practices, farm size was the only significant predictor of adoption, giving limited support to H4. Participants with larger citrus operations were significantly more likely to scout for

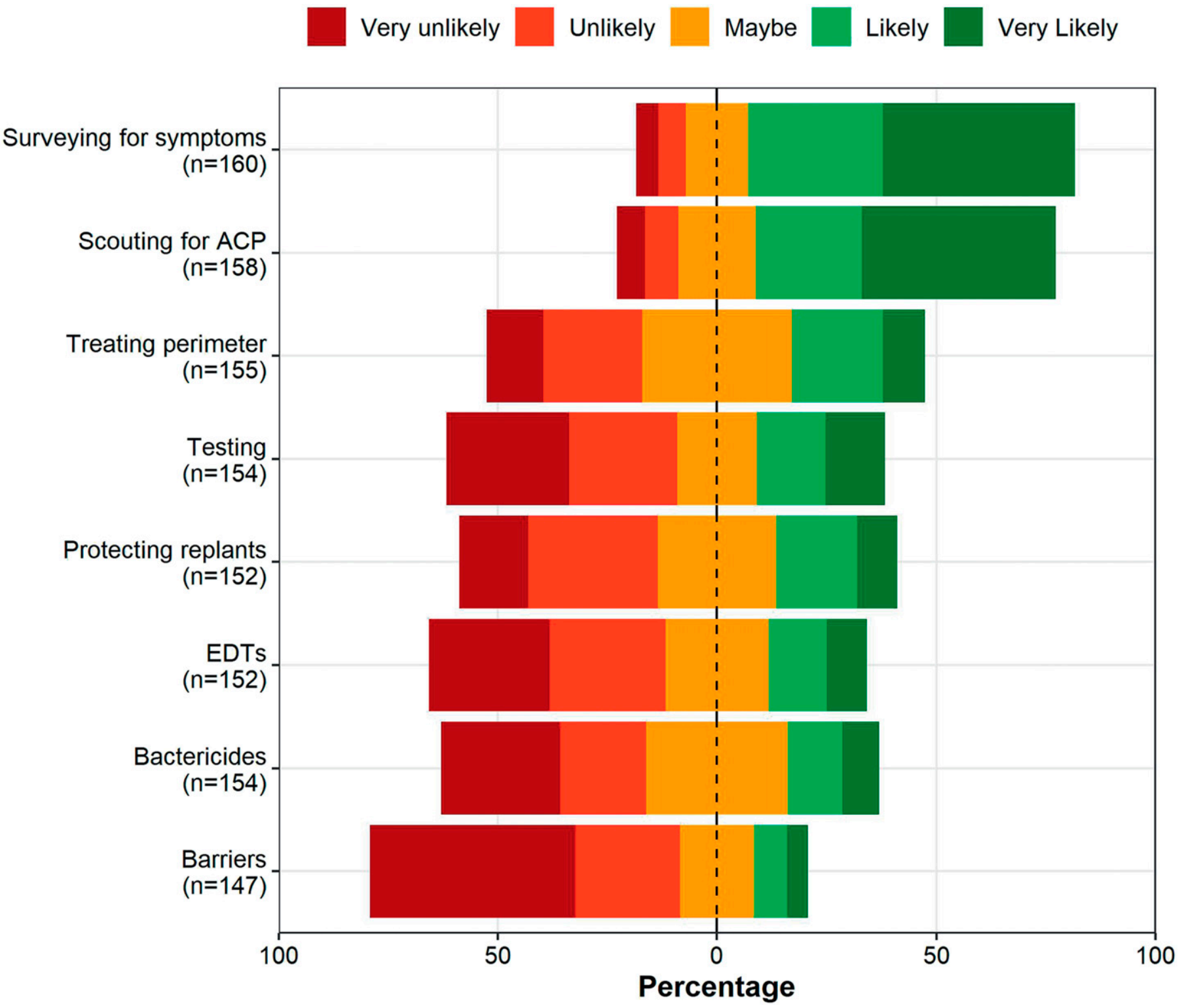



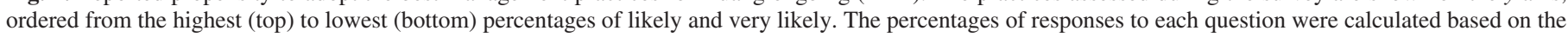


colors on the plot. 
$\mathrm{ACP}$ and test, but they were less likely to perform extra measures to protect new plantings. In fact, for every 1-unit increase in the farm size category, participants had 0.75 -times the odds of being more likely to protect replants. When perceived vulnerability to HLB and the intentions to stay informed and communicate were incorporated into the multivariate ordinal logistic regression model, the participants' role in citrus production, their age, their management system, and the percentage of their income from citrus were not significant predictors of their propensity to adopt any of the HLB management practices.



\section{Regression coefficient value (with $90 \%$ confidence interval)}

Fig. 3. Confidence intervals of the regression coefficients estimated by the multivariate ordinal regression model. The $x$ axis represents the values of the regression coefficients. The $y$ axis identifies the explanatory factor to which the coefficients correspond. The symbols indicate the value of the regression coefficients of the explanatory factors for each practice estimated by the multivariate ordinal regression model, and the whiskers represent the $90 \%$ confidence interval around the estimated value. The symbol shapes represent the integrated pest management (IPM) categories of the practices, and the colors represent the practices according to the legend on the right. Practices have been ordered from highest to lowest propensity to adopt (percentage of likely and very likely according to Fig. 2). 
Estimating the probability of being likely or very likely to adopt the best management practices for HLB. The ultimate goal of using a regression model in this type of study is to be able to make predictions about the adoption of HLB management practices according to the variables that were identified from the existing literature and measured in the study. To facilitate the interpretation of the results, we calculated the predicted probabilities of being likely or very likely to adopt each of the practices in relation to each explanatory factor while keeping the rest of the factors at their mean value (Supplementary Fig. S2).

In particular, we were interested in examining the interaction between perceived vulnerability and the intention to stay informed and communicate with the grower liaison, because the significant regression coefficients of the interaction term suggested that the benefits of informing citrus stakeholders about the different practices might vary depending on the stage of the HLB epidemic. Indeed, as Figure 4 shows, the probability of being likely or very likely to adopt HLB management practices varies depending on the intention to stay informed and communicate with the grower liaison, as represented by the slopes of the different practices, and it also varies depending on the perceived vulnerability to HLB, as represented by the different panels. More importantly, the effects of information and communication on the adoption of some of these practices vary depending on the HLB scenario; this can be seen in the variation in the sign of the slopes of some practices across panels.

For example, when HLB detection is perceived to be unlikely or very unlikely, staying informed and communicating with the grower liaison tends to have a positive effect on the adoption of most practices (top left panels in Fig. 4). When HLB detection is perceived as very unlikely, the probability of surveying for symptoms increases from approximately $30 \%$ for people who are very unlikely to seek information and interact with the liaison to approximately $75 \%$ for people who are very likely to do so. However, when HLB detection is perceived to be likely or very likely, the effect of communication on adoption switches for several practices, and significantly for protecting replants and applying pesticides or repellents to the perimeter. Under high vulnerability to HLB, the adoption of these two practices decreases from 80 to $90 \%$ for people who are very unlikely to stay informed and communicate with the liaison to 20 to $30 \%$ for people who are very likely. Remarkably, the positive effects of communication on the adoption of


\section{Practice}

- Surveying for symptoms

- Scouting for ACP

- Treating perimeter

$\rightarrow$ Testing

$\simeq$ Protecting replants

$\because$ EDTs

- Bactericides

- Barriers

\section{Stay informed \& communicate w/ liaison}

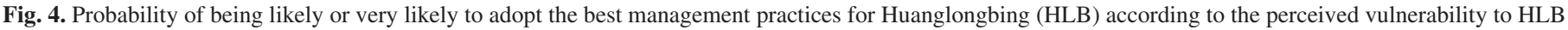
and the propensity to stay informed and communicate with the grower liaison. The practices are colored according to the legend on the right. 
surveys, testing, and EDTs tend to remain stable across the HLB scenarios, thus encouraging the CPDPC to continue promoting the adoption of these monitoring practices.

Interdependence in the propensity to adopt the best management practices for HLB. A preliminary calculation of rank correlations between practices suggested that several of them were likely to be adopted together, particularly those belonging to the same IPM category (Supplementary Table S4). However, rank correlations can only estimate the strength and direction of the monotonic relationship between two variables (i.e., if the propensity to adopt two variables increases or decreases in parallel). One of the strengths of using a multivariate ordinal regression model is that it allows the estimation of the polychoric correlations, which indicate the underlying propensity to adopt each pair of practices when explanatory factors have been considered (Greene and Hensher 2010).

The multivariate ordinal regression model indicated that there were several significant polychoric correlations between practices (Fig. 5; Supplementary Table S5), suggesting that the propensity to adopt different practices is interdependent, as hypothesized (H5). No significant negative correlations were found, indicating that most practices were perceived as complementary, thus supporting the idea of promoting these as a management toolkit. The two practices that had the highest acceptance (Fig. 2), visually inspecting for HLB symptoms and scouting for ACP, had a very high correlation and emerged at the core of the practice adoption network (Fig. 5). Considering that these two practices have been promoted for the longest period of time, are similar to other monitoring protocols that citrus stakeholders routinely follow, and they can be implemented simultaneously while inspecting citrus groves, it was reasonable that they would be highly accepted and highly correlated; however, we were surprised to find that they were not significantly correlated with any other practice, particularly the two other monitoring practices (testing and EDTs).

In contrast, practices that seemed to have low acceptance, such as using barriers, protecting replants, testing, and using EDTs, were highly correlated. These correlations show that practices in the same IPM category are perceived as complementary, and also that

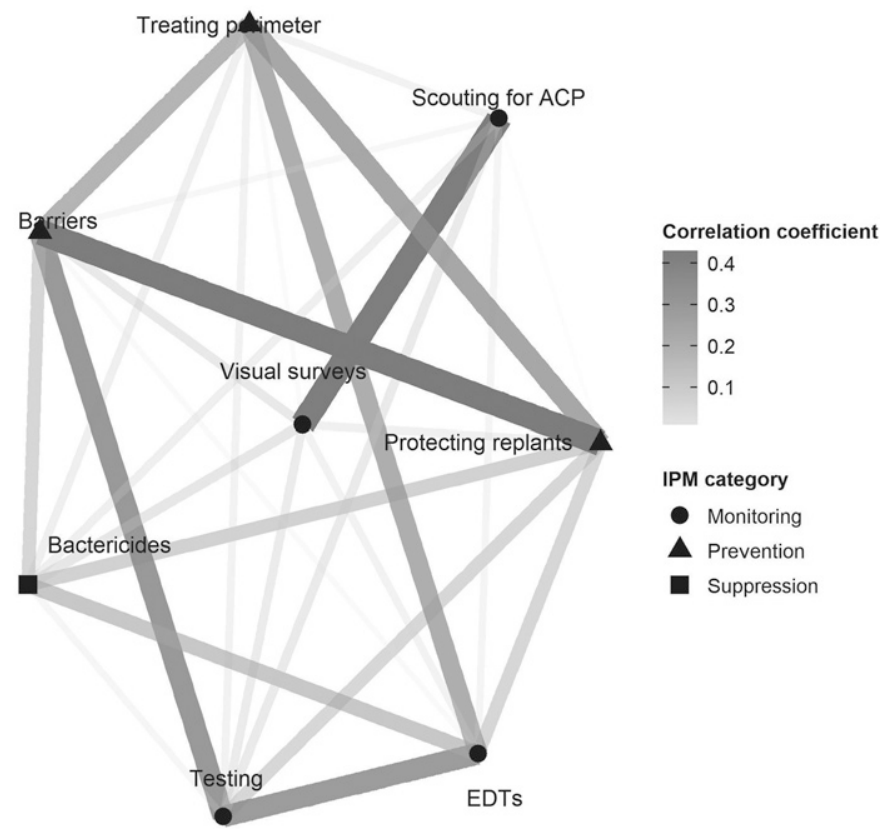

Fig. 5. Interdependence of the propensity to adopt the best management practices for Huanglongbing (HLB), as estimated by the multivariate ordinal logistic regression model. The nodes in the network correspond to each practice, with different shapes for the integrated pest management (IPM) categories of the practices according to the legend on the right. The width and color of the edges between nodes correspond to the correlation coefficients between practices estimated using the multivariate ordinal logistic regression model (Supplementary Table S5). there is another dimension that relates them across categories that was not measured in our model. Additionally, the strong correlation between treating the grove perimeters and voluntarily testing suggests that these two practices may be perceived as two components of a strategy to prevent ACP from entering citrus groves and detect the presence of CLas as soon as possible, which was actually suggested during the presentation of the Voluntary Grower Response Plan. The use of bactericides, which was not officially recommended by the CPDPC, had very low acceptance and was only correlated with the use of EDTs and performing extra measures to protect new plantings. Therefore, it is unclear how California growers might integrate bactericides into HLB management.

\section{DISCUSSION}

The adoption of management practices for invasive plant diseases has been an understudied topic in plant pathology. Early surveys conducted by our group and collaborators in 2015 showed that risk perception and trust in control options were key factors in the decision to join the area-wide management program for HLB in California (Milne et al. 2018). At that time, suppressing the ACP population, removing HLB-positive trees, and using certified plant material were the main management practices recommended to the growers to prevent the spread of HLB (Gottwald 2010). Four years later, these measures seem to have been at least somewhat effective. HLBpositive trees are still confined to residential properties in the Los Angeles metropolitan area, but the number of trees detected increases weekly. As the portfolio of management practices expanded and the Voluntary Grower Response Plan for Huanglongbing was introduced to the citrus industry, it was deemed necessary to assess the propensity to adopt the recommended practices, in order to develop a targeted outreach program that could foster adoption.

In this study, participants were asked about their perception of the likelihood of an HLB detection in their grove in the coming year (July 2019 to June 2020), assuming that it could be one of the key factors prompting them to adopt management practices, in line with the human disease literature (Gaube et al. 2019; Sheeran et al. 2014). Despite some regional differences, the majority of participants believed that HLB detection was unlikely. This low perceived vulnerability was very surprising, especially considering that the ACP is widespread in Southern and Coastal California, and considering that $C$ Las-positive trees and ACP had been detected close to commercial citrus groves in the counties of Riverside and San Bernardino. However, 1 year after the survey, by the end of June 2020, HLBpositive trees had not been detected in any commercial groves, proving that the participants' perception of the likelihood of HLB detection was not inaccurate. In fact, it was negatively correlated with distance from confirmed HLB-positive trees, providing evidence that they were aware of their proximity to infected trees.

Possible explanations for the widespread low perceived vulnerability to HLB could be a general belief that the control program has been effective at preventing HLB spread, for example, by covering citrus trucks with tarps to reduce ACP dispersal (McRoberts and Deniston-Sheets 2021); that the Mediterranean climate in California is not optimal for ACP and/or CLas and, thus, hinders spread (Narouei-Khandan et al. 2016); or that the 1-year horizon in the question about the likelihood of HLB detection was too short. We extended the time horizon in a follow-up survey in Ventura County in October 2019, in which we asked participants about the likelihood of HLB detection in their groves within 1 year and within 5 years (until October of 2024). Interestingly, although $60 \%$ of participants believed that it was unlikely or very unlikely that HLB would be detected in their grove within 1 year, only $16 \%$ of participants believed that within 5 years. The remaining $42 \%$ thought that it was likely or very likely, and $42 \%$ chose maybe, denoting considerable uncertainty about the future (unpublished data). 
Immediately after the presentation of the Voluntary Grower Response Plan for Huanglongbing, our survey showed that not all of the HLB management practices are equally likely to be adopted. Although participants were in favor of surveying for HLB symptoms or scouting for ACP, they were reluctant to install barriers, test trees or ACP, or to consider the use of EDTs. Through the use of a multivariate ordinal regression model, we were able to gain insight into the heterogeneity in adoption, enhancing our understanding of the influence of perceived vulnerability, intentions to stay informed and communicate, and socioeconomic factors on adoption. We were also able to estimate which practices were likely to be adopted together.

This type of model, which was originally developed in a financial context to be freely implemented in R (Hirk et al. 2019), has great potential for practice adoption studies. First, it avoids the simplification of merging different practices into a single adoption score, which has been criticized previously (Puente et al. 2011). Second, it also avoids evaluating each practice in isolation, which may lead to biased and inefficient estimates (as explained by Kassie et al. 2013). Third, it can be used to analyze surveys with ordinal answers, which provide a finer scale to measure propensity to adopt than binary answers that would be analyzed with multivariate probit models (Cai et al. 2019).

In terms of the measured predictors of adoption, our results support the hypothesis that risk perception is a driver of management actions against invasive plant diseases, as proposed by the protection motivation theory in the context of human diseases (Rogers 1975) and by pioneering studies focused on plant pests (Heong and Escalada 1999). The multivariate ordinal logistic regression model indicated that perceived vulnerability to HLB had a positive effect on the probability of scouting for ACP on flush, protecting replants, treating grove perimeters, and using bactericides. However, the impact of perceived vulnerability was significant only for these four practices, and inconsistent relationships between risk perception and practice adoption have been observed in other studies of invasive plant diseases (Breukers et al. 2012; Mankad et al. 2019). Therefore, the evidence collected suggests that cross-sectional studies that predict the adoption of management practices with risk perception as the core predictor might be incomplete, and future longitudinal studies that consider risk perception and practice adoption at several time points (Raude et al. 2019) and include other explanatory factors might be more useful.

In fact, the intention to stay informed and communicate with the grower liaisons had a positive impact on the adoption of most practices, suggesting that the information network that was created by the CPDPC might be a relevant factor in promoting adoption. Remarkably, very few participants said that they did not know who their grower liaison was, and $79 \%$ were likely or very likely to communicate with them, proving their recognition by the community. Nevertheless, the interaction between perceived vulnerability and staying informed and communicating with the liaison suggests that the benefits of promoting HLB management through the CPDPC outreach network might depend on how vulnerable citrus growers feel to HLB, and therefore, on the stage of the HLB epidemic.

People who were more likely to communicate with neighbors had a higher propensity to adopt most practices, confirming the importance of informal communication networks on adoption, even though the effect was only significant for visual surveys and EDTs. Considering that EDTs were negatively impacted by the perceived vulnerability to HLB and not significantly impacted by staying informed and communicating with the grower liaison, neighbor-to-neighbor communication might be a way to promote the adoption of these innovative tools. Previous studies have shown that growers turn to other growers for information about disease management practices (Hillis et al. 2017; Maclean et al. 2019; Sherman et al. 2019), and participatory trials have successfully promoted the adoption of HLB management practices in Texas by letting the growers experience the benefits themselves and spread the word in their communities (Sétamou 2020).

Farm size was identified as the main socioeconomic factor that could impact the adoption of HLB management practices. As the size of the citrus operations increased, there was a positive effect on most practices, which is in line with previous literature about the adoption of other agricultural practices (Prokopy et al. 2019). This effect was significant for scouting for ACP and testing. However, larger citrus operations had a lower probability of taking extra measures to protect new plantings, probably because of the cost associated with these measures (Alferez et al. 2019).

Remarkably, the participants' role in citrus production, their age, their management system, and the percentage of their income from citrus did not have significant effects on the propensity to adopt HLB management practices. Initial rank tests only showed that PCAs were more in favor of using EDTs, that organic growers were less likely to apply extra pesticides or repellents to the perimeter of groves, and that participants who obtained 26 to $50 \%$ of their income from citrus were less likely to communicate with neighbors; while those who obtained 51 to $75 \%$ of their income from citrus were more likely to do so. Although these factors could not be used to predict adoption, the observations might still be useful for the outreach program. PCAs might be more inclined to use EDTs because they often manage multiple operations and need to make rapid, evidence-based decisions; therefore, they could be targeted by the outreach program and the companies providing EDT services to promote these tools among the citrus community. Because PCAs have an increasingly crucial role in advising growers (Eanes et al. 2019; Hillis et al. 2016), outreach activities and workshops aimed specifically at this group could be very beneficial. One of the reasons why organic growers might be less willing to treat grove perimeters is that there are only a few products approved for this use by organic certification programs. Finally, the peculiar effect of income on communication with neighbors is difficult to explain, but no other association was found between income dependency on citrus and propensity to adopt, contrary to previous studies of other invasive plant diseases (Mankad et al. 2019).

In terms of the interdependence between practices, the multivariate ordinal logistic regression model indicated that the propensity to adopt all of the practices was positively correlated, giving support to the idea of a management toolkit. The two monitoring practices that had been promoted from the beginning of the HLB epidemic, scouting for ACP and surveying for symptoms, were highly accepted and highly correlated, providing evidence of the citrus industry's commitment to monitor the vector and the disease. However, they were not correlated with the other two monitoring practices (tests and EDTs), showing a disconnect between visual inspections and more accurate and earlier diagnostic tests. In fact, tests and EDTs were the only two practices not significantly impacted by the intention to stay informed and communicate with the grower liaison, suggesting that they may be more difficult to promote through the CPDPC network. Voluntary testing in particular seemed to have low acceptance and did not seem to be correlated with many practices. This may be due to the uncertainty associated with the consequences of a positive test result and fear of quarantine restrictions, as a CLas-positive qPCR test on leaf material is considered a regulatory positive by the CDFA and it triggers mandatory action (i.e., tree removal and quarantine), while a CLas-positive ACP or a positive EDT test do not trigger mandatory action. One year after this study, the use of one type of EDT (Gottwald et al. 2020) has started in the Coast production area, and a comparable approach to detect ACP is being considered by the CPDPC. Therefore, clarifying the test options available, how they could be integrated in an HLB management plan, and clearly explaining the consequences of a positive result should be a priority for the outreach program to improve surveillance efforts.

Interestingly, some practices that seemed to have low acceptance, such as testing, using EDTs, installing barriers, and protecting replants were highly correlated. Two possible reasons for the low acceptance and correlations between these monitoring and preventive practices could be their novelty and cost, which were not measured in our survey. Previous studies have shown that growers tend to adopt 
practices if the benefits clearly outweigh the costs (Lubell et al. 2011), but adoption is limited for practices with benefits that are difficult to observe or extend over long periods of time (Rogers 2010). Although we did not ask any specific questions about perceived cost, installing barriers would be costly, particularly for groves with extensive perimeters, and EDTs were considered so new that the citrus industry decided not to include them in the Voluntary Grower Response Plan. Bactericides were not included, and they had very low acceptance and were only correlated with the use of EDTs and performing extra measures to protect new plantings, again suggesting that novelty might be a relevant factor for adoption. In addition, bactericides have provided mixed results in other citrus-growing areas (Blaustein et al. 2017), and they raise concerns among consumers about antibiotic residues potentially present on fruit (Jacobs 2017; Jacobs and Adno 2019); therefore, it is unclear how the use of bactericides will unfold as the HLB epidemic progresses in California.

Overall, we believe that future studies of the adoption of plant disease management practices would benefit from the explicit incorporation of behavioral models. One such model is the theory of planned behavior (Ajzen 1991), which has been widely used to explain practice adoption in agriculture (Borges et al. 2019; Daxini et al. 2018), with some pioneering applications in plant disease management (Breukers et al. 2012). The theory of planned behavior proposes that the attitude toward the behavior (the degree to which a person has a favorable or unfavorable evaluation of the behavior), subjective norms (perceived social pressure to perform the behavior), and perceived behavioral control (confidence in the ability to perform the behavior) collectively determine people's behavioral intentions and, ultimately, their behavior (Ajzen 1991). Therefore, asking stakeholders about these three factors in relation to any particular disease management practice might provide a better understanding of their ultimate intentions (Janssen et al. 2020). In fact, the finding that trust in control options had a higher impact on the success of a control campaign against an invasive plant pathogen than risk perception (Milne et al. 2020) is direct evidence of the importance of perceived behavioral control for practice adoption and, ultimately, successful control. Similarly, "values placed on social approval and peer comparisons" (i.e., perceived norms) were key motivating factors for adopting management actions during the first months after the detection of Panama TR4 in Australia (Mankad et al. 2019). In our case, it was hard to assess the citrus stakeholders' attitudes, perceived norms and perceived behavioral control about HLB management practices as they were hearing about some of them for the first time. However, once stakeholders become more familiar with these practices, we believe that future studies aimed at understanding adoption drivers may benefit from focusing more on these types of factors and a careful examination of the relationship between risk perception and protective behavior over time (Gaube et al. 2019), rather than on individual socioeconomic factors that should be used as controls but appear to yield only weak explanatory models of self-reported propensity to adopt management practices.

Conclusions. When an invasive plant disease is introduced in a new territory, management efforts have to be mobilized and coordinated at different scales to face the emerging threat, usually under conditions of high uncertainty and lack of previous experience. Individuals who could potentially be affected by the disease need to react quickly and adopt management practices in a coordinated manner to effectively prevent spread. Under these circumstances, it becomes crucial to understand what factors might drive or prevent the adoption of management practices, and how outreach efforts could be targeted to provide a more effective response to the invasive disease. This study contributes to this understanding by assessing the California citrus industry's propensity to adopt a toolkit of best management practices to prevent the spread of HLB when it was no longer possible to eradicate it, but before it had spread to commercial groves. Our results show that perceived vulnerability to HLB, intentions to stay informed and communicate with formal and informal networks, and farm size could be relevant factors for adoption, and that the adoption of different management practices is interdependent. Further studies that address the stakeholders' attitudes toward the practices, their perceived norms and their perceived behavioral control at different points in time will likely enhance our understanding of the drivers of protective action against invasive diseases, thereby contributing to ensuring the sustainability of crop production under HLB and other emergent plant diseases.

\section{ACKNOWLEDGMENTS}

We thank the citrus growers, ranch managers, PCAs, and other stakeholders who participated in the surveys and provided us with an extremely valuable dataset; the Citrus Research Board for the opportunity to conduct the surveys during the Citrus Growers Educational Seminar Series; Rick Dunn and Robert Johnson for sharing the GIS layers that were used to create Figure 1; the California Department of Food and Agriculture and the Citrus Pest and Disease Prevention Committee for fruitful interaction over several years; Laura Vana from Vienna University of Economics and Business for help with the R package "mvord"; Jessica Rudnick for sharing one of her manuscripts to compare approaches; and Mamoudou Sétamou and an anonymous reviewer for helpful reviews.

\section{LITERATURE CITED}

Ajzen, I. 1991. The theory of planned behavior. Organ. Behav. Hum. Decis. Process. 50:179-211.

Al-Rimawi, F., Hijaz, F., Nehela, Y., Batuman, O., and Killiny, N. 2019. Uptake, translocation, and stability of oxytetracycline and streptomycin in citrus plants. Antibiotics (Basel) 8:196.

Alferez, F., Albrecht, U., Batuman, O., and Graham, J. H. 2019. Individual protective covers (IPCs) prevent young citrus trees from psyllids and infection with CLas and promote vegetative growth. Proceedings of the International Research Conference on Huanglongbing. Riverside, CA.

Bassanezi, R. B., Lopes, S. A., de Miranda, M. P., Wulff, N. A., Volpe, H. X. L., and Ayres, A. J. 2020. Overview of citrus huanglongbing spread and management strategies in Brazil. Trop. Plant Pathol. 45:251-264.

Bassanezi, R. B., Montesino, L. H., Gimenes-Fernandes, N., Yamamoto, P. T., Gottwald, T. R., Amorim, L., and Filho, A. B. 2013. Efficacy of area-wide inoculum reduction and vector control on temporal progress of Huanglongbing in young sweet orange plantings. Plant Dis. 97:789-796.

Blaustein, R. A., Lorca, G. L., and Teplitski, M. 2017. Challenges for managing Candidatus Liberibacter spp. (Huanglongbing disease pathogen): Current control measures and future directions. Phytopathology 108:424-435.

Borges, J. A. R., Domingues, C. H. de F., Caldara, F. R., da Rosa, N. P., Senger, I., and Guidolin, D. G. F. 2019. Identifying the factors impacting on farmers' intention to adopt animal friendly practices. Prev. Vet. Med. 170:104718.

Breukers, A., van Asseldonk, M., Bremmer, J., and Beekman, V. 2012. Understanding growers' decisions to manage invasive pathogens at the farm level. Phytopathology 102:609-619.

Brewer, N. T., Weinstein, N. D., Cuite, C. L., and Herrington, J. E., Jr. 2004. Risk perceptions and their relation to risk behavior. Ann. Behav. Med. 27: $125-130$.

Bryer, J., and Speerschneider, K. 2016. Likert: Analysis and visualization Likert items. https://CRAN.R-project.org/package=likert

Cai, J., Zhang, L., Tang, J., and Pan, D. 2019. Adoption of multiple sustainable manure treatment technologies by pig farmers in rural China: A case study of Poyang Lake Region. Sustainability 11:6458.

Chaves, B., and Riley, J. 2001. Determination of factors influencing integrated pest management adoption in coffee berry borer in Colombian farms. Agric. Ecosyst. Environ. 87:159-177.

CPDPP. 2019. Best practices in response to Huanglongbing in California citrus, California Citrus Pest and Disease Prevention Program (CPDPP). https:// citrusinsider.org/wp-content/uploads/2019/06/Voluntary-Actions-Best-Prac tices-COMPLETE-FINAL.pdf

CPDPP. 2020a. CLas-positive Asian citrus psyllid found in Riverside commercial grove, California Citrus Pest and Disease Prevention Program (CPDPP). https://citrusinsider.org/2020/08/07/clas-positive-asian-citrus-psyllid-foundin-riverside-commercial-grove/

CPDPP. 2020b. HLB quarantine and treatment areas (CDFA). Citrus insider. Citrus Pest and Disease Prevention Program (CPDPP). http://www.citrus insider.org/maps-and-quarantines/

Daxini, A., O’Donoghue, C., Ryan, M., Buckley, C., Barnes, A. P., and Daly, K. 2018. Which factors influence farmers' intentions to adopt nutrient management planning? J. Environ. Manage. 224:350-360. 
De Leon, A. 2009. Assembly Bill No. 281 Citrus disease prevention: California Citrus Pest and Disease Prevention Committee. https://leginfo.legislature.ca. gov/faces/billTextClient.xhtml?bill_id=200920100AB281

Eanes, F. R., Singh, A. S., Bulla, B. R., Ranjan, P., Fales, M., Wickerham, B., Doran, P. J., and Prokopy, L. S. 2019. Crop advisers as conservation intermediaries: Perceptions and policy implications for relying on nontraditional partners to increase U.S. farmers' adoption of soil and water conservation practices. Land Use Policy 81:360-370.

Farrar, J. J., Baur, M. E., and Elliott, S. F. 2016. Adoption of IPM practices in grape, tree fruit, and nut production in the western United States. J. Integr. Pest Manag. 7:8.

Fernandez-Cornejo, J., Beach, E. D., and Huang, W.-Y. 1994. The adoption of IPM techniques by vegetable growers in Florida, Michigan and Texas. J. Agric. Appl. Econ. 26:158-172.

Fresno CAC. 2019. Fresno County Annual Crop \& Livestock Report 2018, Fresno County Agricultural Commissioner (CAC). https://www.co.fresno. ca.us/Home/ShowDocument?id=37986

Gaube, S., Lermer, E., and Fischer, P. 2019. The concept of risk perception in health-related behavior theory and behavior change. Pages 101-118 in: Perceived Safety: A Multidisciplinary Perspective. M. Raue, B. Streicher, and E. Lermer, eds. Springer International Publishing, Cham, Switzerland.

Gottwald, T., Poole, G., McCollum, T., Hall, D., Hartung, J., Bai, J., Luo, W., Posny, D., Duan, Y.-P., Taylor, E., da Graça, J., Polek, M., Louws, F., and Schneider, W. 2020. Canine olfactory detection of a vectored phytobacterial pathogen, Liberibacter asiaticus, and integration with disease control. Proc. Natl. Acad. Sci. USA 117:3492-3501.

Gottwald, T. R. 2010. Current epidemiological understanding of citrus Huanglongbing. Annu. Rev. Phytopathol. 48:119-139.

Grafton-Cardwell, E. E. 2020. Management of Asian citrus psyllid in California. Pages 250-257 in: Asian Citrus Psyllid: Biology, Ecology and Management of the Huanglongbing Vector. J. A. Qureshi and P. A. Stansly, eds. CAB International, Wallingford, United Kingdom.

Grafton-Cardwell, E. E., Stelinski, L. L., and Stansly, P. A. 2013. Biology and management of Asian citrus psyllid, vector of the Huanglongbing pathogens. Annu. Rev. Entomol. 58:413-432.

Graham, J. H., Gottwald, T. R., and Sétamou, M. 2020. Status of Huanglongbing (HLB) outbreaks in Florida, California and Texas. Trop. Plant Pathol. 45: 265-278

Greene, W. H., and Hensher, D. A. 2010. Modeling ordered choices: A primer. Pages 41-230 in: Modeling Ordered Choices: A Primer. Cambridge University Press, New York.

Harrell, Jr., F. E., and Dupont, M. C. 2020. Hmisc: Harrell Miscellaneous. https://cran.r-project.org/web/packages/Hmisc/index.html

Heong, K. L., and Escalada, M. M. 1999. Quantifying rice farmers' pest management decisions: Beliefs and subjective norms in stem borer control. Crop Prot. 18:315-322.

Hillis, V., Lubell, M., Kaplan, J., and Baumgartner, K. 2017. Preventative disease management and grower decision making: A case study of California wine-grape growers. Phytopathology 107:704-710.

Hillis, V., Lubell, M., Kaplan, J., Doll, D., and Baumgartner, K. 2016. The role of pest control advisers in preventative management of grapevine trunk diseases. Phytopathology 106:339-347.

Hirk, R., Hornik, K., and Vana, L. 2019. Multivariate ordinal regression models: an analysis of corporate credit ratings. Stat. Methods Appl. 28:507-539.

Hirk, R., Hornik, K., and Vana, L. 2020. mvord: an R package for fitting multivariate ordinal regression models. J. Stat. Softw. 93:1-41.

Hoffman, M., Lubell, M., and Hillis, V. 2015. Network-smart extension could catalyze social learning. Calif. Agric. 69:113-122.

Hu, J., Jiang, J., and Wang, N. 2018. Control of citrus huanglongbing via trunk injection of plant defense activators and antibiotics. Phytopathology 108: 186-195.

Imperial CAC. 2019. Imperial County Agricultural Crop and Livestock Report 2018, Imperial County Agricultural Commissioner (CAC). https://agcom. imperialcounty.org/crop-reports/

Jacobs, A. 2017. Spraying antibiotics to fight citrus scourge doesn't help, study finds. The New York Times, August 16. https:/www.nytimes.com/2019/08/ 16/health/antibiotics-citrus-spraying.html

Jacobs, A., and Adno, M. 2019. Citrus farmers facing deadly bacteria turn to antibiotics, alarming health officials. The New York Times, May 17. https://www.nytimes.com/2019/05/17/health/antibiotics-oranges-florida.html? searchResultPosition $=2$

Janssen, E. M., Mourits, M. C. M., van der Fels-Klerx, H. J., and Oude Lansink, A. G. J. M. 2020. Factors underlying Dutch farmers' intentions to adapt their agronomic management to reduce Fusarium species infection in wheat. PLoS One 15:e0237460.

Kaine, G., and Bewsell, D. 2008. Adoption of Integrated Pest Management by apple growers: The role of context. Int. J. Pest Manage. 54:255-265.

Kassie, M., Jaleta, M., Shiferaw, B., Mmbando, F., and Mekuria, M. 2013. Adoption of interrelated sustainable agricultural practices in smallholder systems: Evidence from rural Tanzania. Technol. Forecast. Soc. Change 80:525-540.

Kern CAC. 2019. 2018 Kern County Agricultural Crop Report, Kern County Agricultural Commissioner (CAC). http://www.kernag.com/caap/cropreports/crop10_19/crop2018.pdf

Kuchment, A. 2013. The end of orange juice. Sci. Am. 308:52-59.

Kumagai, L. B., LeVesque, C. S., Blomquist, C. L., Madishetty, K., Guo, Y., Woods, P.W., Rooney-Latham, S., Rascoe, J., Gallindo, T., Schnabel, D., and Polek, M. 2013. First report of Candidatus Liberibacter asiaticus associated with Citrus Huanglongbing in California. Plant Dis. 97:283.

Liu, T., Bruins, J. F. R., and Heberling, T. M. 2018. Factors influencing farmers' adoption of best management practices: a review and synthesis. Sustainability 10:432.

Lubell, M., Hillis, V., and Hoffman, M. 2011. Innovation, cooperation, and the perceived benefits and costs of sustainable agriculture practices. Ecol. Soc. $16: 23$.

Maclean, K., Farbotko, C., and Robinson, C. J. 2019. Who do growers trust? Engaging biosecurity knowledge to negotiate risk management in the north Queensland banana industry, Australia. J. Rural Stud. 67:101-110.

Madera CAC. 2019. Crop and Livestock Report Madera County 2018, Madera County Agricultural Commissioner (CAC). https://www.maderacounty. com/home/showdocument?id=17417

Mankad, A., Zhang, A., and Curnock, M. 2019. Motivational drivers of action in response to an environmental biosecurity incursion. J. Environ. Manage. 232:851-857.

McCollum, G., and Baldwin, E. 2016. Huanglongbing: devastating disease of citrus. Pages 315-361 in: Horticultural Reviews. J. Janick, ed. Vol. 44. John Wiley \& Sons, Ltd., Hoboken, NJ.

McFadden, D. 1974. Conditional logit analysis of qualitative choice behavior. Pages 105-142 in: Frontiers in Econometrics. P. Zarembka, ed. Academic Press, New York, NY.

McKinnon Edwards, S., Auguie, B., Jackman, S., Wickham, H., and Chang, W. 2020. Lemon: Freshing up your "ggplot2" plots. https://cran.r-project.org/ web/packages/lemon/index.html

McRoberts, N., and Deniston-Sheets, H. 2021. Citrus tarping requirements reduce ACP movement. Citrograph 12:34-37.

McRoberts, N., Hall, C., Madden, L. V., and Hughes, G. 2011. Perceptions of disease risk: From social construction of subjective judgments to rational decision making. Phytopathology 101:654-665.

Milne, A. E., Gottwald, T., Parnell, S. R., Alonso Chavez, V., and van den Bosch, F. 2020. What makes or breaks a campaign to stop an invading plant pathogen? PLOS Comput. Biol. 16:e1007570.

Milne, A. E., Teiken, C., Deledalle, F., van den Bosch, F., Gottwald, T. R., and McRoberts, N. 2018. Growers' risk perception and trust in control options for huanglongbing citrus-disease in Florida and California. Crop Prot. 114:177-186.

Narouei-Khandan, H. A., Halbert, S. E., Worner, S. P., and van Bruggen, A. H. C. 2016. Global climate suitability of citrus huanglongbing and its vector, the Asian citrus psyllid, using two correlative species distribution modeling approaches, with emphasis on the USA. Eur. J. Plant Pathol. 144:655-670.

Pedersen, T. L. 2020. ggraph: An implementation of grammar of graphics for graphs and networks. https://cran.r-project.org/web/packages/ggraph/index. html

Prokopy, L. S., Floress, K., Arbuckle, J. G., Church, S. P., Eanes, F. R., Gao, Y., Gramig, B. M., Ranjan, P., and Singh, A. S. 2019. Adoption of agricultural conservation practices in the United States: evidence from 35 years of quantitative literature. J. Soil Water Conserv. 74:520-534.

Puente, M., Darnall, N., and Forkner, R. E. 2011. Assessing integrated pest management adoption: measurement problems and policy implications. Environ. Manage. 48:1013-1023.

R Foundation for Statistical Computing. 2019. R: A Language and Environment for Statistical Computing. R Foundation for Statistical Computing, Vienna, Austria.

Raude, J., MCColl, JK., Flamand, C., and Apostolidis, T. 2019. Understanding health behaviour changes in response to outbreaks: Findings from a longitudinal study of a large epidemic of mosquito-borne disease. Soc. Sci. Med. 230:184-193.

Ritter, C., Jansen, J., Roche, S., Kelton, D. F., Adams, C. L., Orsel, K., Erskine, R. J., Benedictus, G., Lam, T. J. G. M., Barkema, H. W. 2017. Invited review: Determinants of farmers' adoption of management-based strategies for infectious disease prevention and control. J. Dairy Sci. 100:3329-3347.

Riverside CAC. 2019. Riverside County Agricultural Production Report 2018, Riverside County Agricultural Commissioner (CAC). https://www.rivco awm.org/Portals/0/PDF/2018-Crop-Report.pdf

Robles González, M. M., Orozco Santos, M., Manzanilla Ramírez, M. Á., Velázquez Monreal, J. J., Medina Urrutia, V. M., and Stuchi, E. S. 2018. Experiences with huanglongbing in Mexican lemon in the State of Colima, Mexico. Citrus Res. Technol. 39:e1039. 
Rogers, E. M. 2010. Diffusion of Innovations, 4th ed. Simon and Schuster, New York.

Rogers, R. W. 1975. A protection motivation theory of fear appeals and attitude change. J. Psychol. 91:93-114.

Rogers, R. W. 1985. Cognitive and psychological processes in fear appeals and attitude change: a revised theory of protection motivation. Pages 153-176 in: Social Psychophysiology. J. Cacioppo and R. Petty, eds. Guilford Press, New York.

San Bernardino CAC. 2019. Annual Crop Report 2018 San Bernardino County, San Bernardino County Agricultural Commissioner (CAC). http://cms. sbcounty.gov/Portals/13/CropReports/2018CropReport.pdf?ver=2020-0320-152920-220

San Diego CAC. 2019. 2018 Crop Statistics and Annual Report, San Diego County Agricultural Commissioner (CAC). https://www.sandiegocounty. gov/content/dam/sdc/awm/docs/2018_Crop_Report_web.pdf

Santa Barbara CAC. 2019. 2018 Agricultural Production Report County of Santa Barbara, Santa Barbara County Agricultural Commissioner (CAC). https://countyofsb.org/uploadedFiles/agcomm/Content/Other/crops/2018.pdf

Sétamou, M. 2020. Area-wide management of Asian citrus psyllid in Texas. Pages 234-249 in: Asian Citrus Psyllid. Biology, Ecology and Management of the Huanglongbing Vector. J. A. Qureshi and P. A. Stansly, eds. CAB International, Wallingford, U.K.

Sétamou, M., Alabi, O. J., Kunta, M., Dale, J., and daGraca, J. 2020. Distribution of Candidatus Liberibacter asiaticus in citrus and the Asian citrus psyllid in Texas over a decade. Plant Dis. 104:1118-1126.

Sheeran, P., Harris, P. R., and Epton, T. 2014. Does heightening risk appraisals change people's intentions and behavior? A meta-analysis of experimental studies. Psychol. Bull. 140:511-543.

Sheeran, P., Klein, W. M. P., and Rothman, A. J. 2017. Health behavior change: moving from observation to intervention. Annu. Rev. Psychol. 68:573-600.

Sherman, J., Burke, J. M., and Gent, D. H. 2019. Cooperation and coordination in plant disease management. Phytopathology 109:1720-1731.

Sherman, J., and Gent, D. H. 2014. Concepts of sustainability, motivations for pest management approaches, and implications for communicating change. Plant Dis. 98:1024-1035.

Simberloff, D., Martin, J.-L., Genovesi, P., Maris, V., Wardle, D. A., Aronson, J., Courchamp, F., Galil, B., García-Berthou, E., Pascal, M., Pyšek, P., Sousa, R., Tabacchi, E., Vilà, M. 2013. Impacts of biological invasions: What's what and the way forward. Trends Ecol. Evol. 28:58-66.
Singerman, A., Lence, S. H., and Useche, P. 2017. Is area-wide pest management useful? The case of citrus greening. Appl. Econ. Perspect. Policy 39: 609-634.

Stallman, H. R., and James, H. S. 2015. Determinants affecting farmers' willingness to cooperate to control pests. Ecol. Econ. 117:182-192.

Stallman, H. R., and James, H. S. 2017. Farmers' willingness to cooperate in ecosystem service provision: does trust matter? Ann. Public Coop. Econ. 88:5-31.

Tulare CAC. 2019. Tulare County Crop \& Livestock Report 2018, Tulare County Agricultural Commissioner (CAC). https://agcomm.co.tulare.ca.us/ ag/index.cfm/standards-and-quarantine/crop-reports1/crop-reports-2011-2020/ 2018-crop-report/

USDA-NASS. 2017. 2016 Certified Organic Survey, United States Department of Agriculture, National Agricultural Statistics Service. https://downloads. usda.library.cornell.edu/usda-esmis/files/zg64tk92g/70795b52w/4m90dz33q/ OrganicProduction-09-20-2017 correction.pdf

USDA-NASS. 2018. 2018 California Citrus Acreage Report, United States Department of Agriculture, National Agricultural Statistics Service. https:// www.nass.usda.gov/Publications/AgCensus/2017/Full_Report/Volume_1, Chapter_1_State_Level/California/st06_1_0037_0037.pdf

USDA-NASS. 2019. 2017 Census of Agriculture, United States Department of Agriculture, National Agricultural Statistics Service. https://www.nass.usda. gov/Publications/AgCensus/2017/Full_Report/Volume_1,_Chapter_1_US/ usv1.pdf

Ventura CAC. 2019. 2018 Crop \& Livestock Report County of Ventura, Ventura County Agricultural Commissioner (CAC). https://vcportal.ventura.org/ AgComm/docs/crop-reports/Ag\%20Comm\%202018\%20Crop\%20Report $\% 2008-02-19 \% 20$ web.pdf

Wang, N. 2019. The citrus Huanglongbing crisis and potential solutions. Mol. Plant 12:607-609.

Weinstein, N. D., and Nicolich, M. 1993. Correct and incorrect interpretations of correlations between risk perceptions and risk behaviors. Health Psychol. $12: 235-245$.

Wickham, H. 2016. ggplot2: Elegant Graphics for Data Analysis. SpringerVerlag, New York.

Zeileis, A., and Hothorn, T. 2002. Diagnostic checking in regression relationships. R News 2:7-10. 